\title{
Community Service Provider's Stories: COVID-19 Impacts and Vulnerable Canadians
}

\author{
Nimo Bokore, ${ }^{1, *} \&$ Jillian Premachuk ${ }^{2}$ \\ ${ }^{1}$ School of Social Work, Carleton University, Canada \\ *Corresponding author: School of Social Work, Carleton University, Canada
}

Received: February 6, 2021 Accepted: March 10, 2021 Published: June 15, 2021

doi:10.5296/jsr.v12i2.18272 URL: https://doi.org/10.5296/jsr.v12i2.18272

\begin{abstract}
In 2020 a global health pandemic began causing significant life challenges for most populations around the world. For vulnerable groups in Canada, like newcomers and refugees, the COVID19 global health crisis amplified pre-existing inequalities and barriers. Given the previous understandings of racial inequality in Canada, we began an online discussion with a group of social service providers to explore how newcomers and refugees are impacted by the social lockdowns, physical distance, and the closures of many services. As a result, we collected informative stories that tell how the pandemic disproportionately and distinctly impact newcomers and refugees, resulting in new challenges finding employment, access to educational services for their families, and maintaining an adequate social and spiritual connection. We also found out how community service provision drastically changed throughout the COVID-19 pandemic, resulting in additional challenges and barriers for marginalized communities.
\end{abstract}

Keywords: COVID-19, service providers, stories, vulnerable groups 


\section{Introduction}

The outbreak of the COVID-19 pandemic began in early 2020, with news of disproportionate deaths among Black people in the United States and a lack of ethnic data available for analysis. Similarly, in Canada, issues of racial inequality during the pandemic had not been mentioned in health reports until community activists started sharing their concerns through social media. Later, Toronto Public Health announced it would begin collecting data to explore the same impacts (Alliance of Healthier Communities 2020, Bowden, 2020; Bowden \& Cain, 2020). As the world seemingly changed overnight, the authors started to rethink service disparities for Canada's communities. The initial conversations began with a question about how COVID-19 impacts vulnerable groups such as Canada's newcomers as they start working toward rebuilding their new lives?

Our questions and discussions were re-affirmed when the Institute for Clinical Evaluative Sciences (ICES) released a shocking report in September 2020. The report shows how in Ontario, Canada, refugees and newcomers accounted for nearly half of all positive COVID-19 cases reported to date, despite only representing about a quarter of the Ontario population (Guttmann et al., 2020). These disproportionate rates of COVID-19 infections only scratch the surface of this topic.

This paper aims to explore the pandemic-related stressors for marginalized communities and service providers in their attempt to continue providing services to the community. It explores the pandemic's impact on those living below the margins and supporting each other through online discussions and information sharing. With direct insight from service providers, this paper explores the pandemic-related stressors and experiences service providers go through in their attempt to continue providing services to their communities. These discussions were based on service providers' perspectives, who held online meetings during the pandemic's initial months.

These conversations highlight the current global health crisis and amplifying existing social inequalities, including the widening gap between the haves and have-nots, vulnerability to life's challenges, and the overall impact on health and wellbeing. In recent years, the difference in access to health care and general wellbeing has been discussed globally, particularly regarding population health and predicting a global pandemic (such as the current coronavirus). Health researchers, community advocates, and other interest groups have warned about these issues and explored ways of decreasing the gap through policy and social justice-based action (Alliance of Healthier Communities, 2020; Bill and Melinda Gates Foundation, 2020; Bowden, 2020; Stöhr, 2005).

One of these forewarnings came from powerful interest groups, including one of the world's billionaires, Bill Gates. He predicted the world would be unprepared for a global health pandemic in a TED Talk presentation in 2015 (Gates, 2015). Gates spoke of the possibility of an epidemic worse than the Ebola crisis (which disproportionally affected African countries see Elliot, 2003; Levich, 2015), highlighting the world is unprepared for when this could happen. What is often not discussed widely, both in previous conversations and now in the ongoing pandemic, is the disproportionate impact the COVID-19 pandemic will have on the 
world's poorest countries and populations. These countries, mostly in Africa, struggle with preexisting challenges, including economic dependency based on aid from western nations and a lack of health care structures to overcome a pandemic (Oluwatayo \& Ojo, 2018).

\subsection{Inequalities, Social Justice and Community Practice}

In the coming years, as policy analysts, historians, other academic researchers, and social activists analyze the impact of COVID-19 on marginalized communities living in the West and developing nations worldwide, the ongoing and alarming economic disparities and implications will be explained (Oluwatayo \& Ojo, 2018; Parker, 2002). It is a fact that health and economic inequalities were visible before the COVID-19 pandemic for these marginalized populations (Alliance of Healthier Communities, 2020; Andersen \& Collins, 2013; Bowden \& Cain, 2020; Brown et al., 2000; De Maio, 2010; Gates, 2015). However, what is missing in these discussions is how the paradigm shift from focusing on social welfare issues to a neoliberal-based financial plan continues to be promoted by various governments and political groups in the past four decades.

It is a long-overdue discussion that began when Western politicians such as Ronald Reagan, Margaret Thatcher, and Brian Mulroney in Canada started to vocally or silently move away from collective agendas. The move away from Keynesian state response to social programs while adapting pro-business and corporate plans continues to negatively impact the most marginalized communities (Brown, 2001; Chappell, 2014; Raphael, 2011; Wahl, 2011). The long-lasting effects of these changes are visible in how the current pandemic has disproportionately impacted specific communities. For example, in late March 2020, online discussions among Black service providers and other marginalized groups began to point out the lack of ethnic-based data available. This conversation is imperative to understand the pandemic's intersecting impacts and plan future responses to similar situations.

Immigrants and newcomers arrive in Canada each year, often joining existing marginalized communities due to a lack of affordable housing, employment, and social connections. These new arrivals from "non-traditional" source countries enrich Canada's demographic picture and are vital in participating in future labour forces and providing a significant economic contribution. For example, $61 \%$ of Canada's population growth comes through immigration (Statistics Canada, 2019). These conversations came up during online discussions addressing these issues and the persisting labour market barriers. The authors also discussed with service providers how the pandemic lockdown affected most of the available jobs that newcomers often get. While those with language proficiency joined the essential or frontline services, such as working in grocery stores or food delivery, others are locked down with their children at home, delaying the process of labour market entry.

This stressful condition contributes to their vulnerability, lifestyle changes, and existing preCOVID-19 resettlement challenges, directly impacting immigrant and resettled refugees (De Maio, 2010; Raphael, 2011). For these new communities, the lockdown and social distancing requirements also unveil the limited social support these groups received before the pandemic, increasingly seeking service providers' help to stay connected. 


\subsection{Lockdown, Social Support and Wellbeing}

Through online discussion and personal experience as service providers, the authors of this paper witnessed the impact these issues have on the communities. Marginalized communities, especially racialized communities, have been historically and currently underserved. This reality is systemically informed and maintained through discrimination, limited access to resources, and other socioeconomic disparities. As professionals and community members from these disenfranchised communities, service providers occupy dual identities, giving them first-hand knowledge of the gaps in service provision and service attainment from both sides.

Most of the social support that marginalized communities receive, especially racialized communities, often comes from grassroots community agencies were participants of these online discussion work. In many ways, these agencies and service providers have mastered the art of 'stretching' resources to facilitate marginalized people's needs, which informs deep, trusting relationships (Brown et al., 2000). External and internal social supports are crucial for marginalized communities functioning because they deal with systemically maintained stressors. The service providers talked about the importance of social support known to decrease those generally present stressors in their lives (McKenzie et al., 2016). In these discussions, each service provider addressed their concerns regarding the implications of the lack of social support, especially with COVID-19 isolation and restrictions, which are dire to these already marginalized communities.

Throughout this paper, social support is referenced and defined as the interactions with family members, friends, peers, and service providers. The interactions with service providers are a new contribution to this argument of what constitutes social supports, as most of the newcomers communicate regularly with their service providers, often building a positive relationship while seeking information and emotional support, often in their own languages. With the global pandemic, service providers' face-to-face support is limited amid lockdowns, social distancing, additional new safety protocols requiring masks and wearing other protective equipment.

When we asked service providers about the importance of in-person services, they explained how crucial it is to enhance newcomers' coping mechanisms, moderate the impact of resettlement stressors, and promote health and wellbeing. Health researchers argue that social support is one of the underlying determinants of health for this group of people, especially when dealing with resettlement stressors (Chadwick \& Collins, 2015; De Maio, 2010; Raphael, 2011; Simich et al. 2005). The service providers also identified how social support for this group is significant, especially those coming from a communal culture and historical trauma. They talked about how specific religious practices promote social support, defining certain benefits, such as Muslims exchanging good deeds, including participating in collective prayers (Pargament \& Park, 1997; Park, 2005). While discussing social support, the service providers talked about how some newcomers maintain social connections by using creative solutions using Paltalk, WhatsApp, Zoom, and other group talk services.

Others use religious and spiritual methods for copying. Understanding the role of spirituality during stressful times is acknowledged by some service providers to enhance copying. For decades, researchers have debated the role religious practices have on wellbeing (Elliott \& 
Hayward, 2009). Sigmund Freud, for example, considered religion to be a psychopathological, neurotic wish-fulfilment. In contrast, other scientists saw it as a powerful coping mechanism (Pargament \& Park, 1997) or a way of finding fulfilment and meaning in life (Park, 2005). One of the service providers spoke about Muslim refugees and existing religious and cultural support systems, explaining how this practice allowed some of his clients to manage pre and during COVID-19 to cope with resettlement challenges.

Service providers highlighted the benefits of community houses and resource centers for their clients. These community spaces offer places to get social support, help with literacy issues, improve language capacity and social connection.

Nostalgically, one manager explained how pre-COVID-19, their agency provided a wide range of programs and services that aimed to improve the quality of life for multicultural families and households living on a fixed or low income. Despite the challenges of virtual services, this manager explained how she and her staff still work resourcefully with clients. From the firsthand experience, she and her team are still part of the community service providers who observe marginalized community members' needs or concerns to facilitate solutions. This pandemic has disrupted this necessary and mutually beneficial relationship between client and service provider since individuals are not frequenting these face-to-face spaces in the same manner as before. However, they continue to provide and learn from the community about what is needed as much as possible. The concern lies in knowing their needs still exist and are only heightened by pandemic-related stressors. If these individuals are not visiting their common spaces to access social support necessary for their livelihood, there could be only one assumption given their social and financial locations; they are struggling in isolation (Bowden \& Cain, 2020).

For youth, city spaces serve as the 'equalizer' that allows them to partake in extracurricular activities. Due to limited financial capacity, recreational needs for marginalized community members are met through the available community-based public areas, offered free or at a low cost. The pandemic restricted many racialized youths' wellness opportunities, often attached to their ability to play basketball or soccer in the city park. This activity contrasts with their nonracialized counterparts who have access to extracurricular activities in their homes or inside controlled environments, i.e. playing the violin, piano, or hockey (Bowden \& Cain, 2020). For marginalized youth, lack of access to these crucial spaces is imperative for their mental wellness, and overall livelihood is an area researchers will explore in the coming years.

\section{Methodology}

This paper came to be after service providers gathered virtually to discuss the challenges of the initial lockdown changes in 2020 due to the COVID-19 pandemic. The conversations began with acknowledging the overwhelming changes to our way of life resulting from COVID-19. Changes that affected even the authors of this paper include relying on technology and virtual meetings to have these discussions and share their thoughts. In these virtual meetings, we shared current problems and insights in response to considering who is impacted by COVID- 
19 and the challenges of providing services to these vulnerable groups. From the beginning, the authors began to reflect on their personal stories, defining pre-existing and structural issues from a highly gendered global economy that distinctly impacts women and specific racialized and marginalized communities. We discussed the conditions that put women in a vulnerable position, including experiencing severe poverty, especially difficult for single mothers as the head of the household, often with multiple children. Some talked about what life looks like during lockdown, homeschooling their children without adequate knowledge, time, support, resources, and feelings of anxiety, ultimately impacting their overall wellbeing. Together, the co-authors brought the rich insight of each service provider who participated in continuing the conversation to this paper.

This study used purposive sampling methods, using community connections to invite service providers to discuss the pandemic's impact on the vulnerable groups they serve. This qualitative approach allowed for genuine community insight rather than a rigorous research study following the required research study process. This ad hoc online conversation method allowed us to reach out to Black faculty members at Carleton University and service providers working at multiple community agencies in Ontario, Canada. Due to this project's timing, which began a month after the initial lockdown, the initial discussion grew from email conversations and online meetings as a support group during the pandemic. Eight service providers continue to have these monthly discussions where specific barrier-related themes emerged. The group then decided to share this knowledge through publication.

We acknowledge the challenges and issues of discussing personal stories over virtual meetings and multiple email exchanges. These conversations are meant to initiate pandemic-related online discussions, designed to support each other while keeping the agencies' confidentiality. There are no identifying points or personal stories of their clients or workplaces mentioned for this reason. It is an information exchange triangulated with document analysis of current COVID-19 literature, new reports, and its impacts on specific communities for this paper's benefit. We focused on these personal accounts using narrative inquiry to provide more compelling, real-time stories based on each service provider's experiences, the world in the time of COVID-19, and impacts on individual communities (Webster \& Mertova, 2007, p 3). Our conversations followed feminist narratives, used to explore participants' stories while equally encouraging each other to be active agents of our lives (Amoah, 2013; Collins, 2000; Collins, 2019; Hooks, 1984; Tracy, 2013). This process allowed us to share our own stories as we struggle with the fear of the pandemic, the lockdown, and the economic impact on our communities and individual livelihoods. We held these conversations with a set of open and semi-structured narrative research questions that allowed us to use a life-history approach to practitioners' experiences or challenges with food security in the context of the pandemic lockdown (De Haene et al., 2010). When analyzing themes discussed, we focused on the participant's narrative as they focused on specific challenges in the context of the pandemic, lockdown measures, barriers to services, and how barring witness to these community issues shaped their understanding of service the role of culture and community in resilience building.

We asked exploratory questions to find out: who is impacted the most by the enforced social lockdown? What changes are service providers dealing with and adapted to continue helping 
the vulnerable communities they are servicing? We continued these conversations with questions we felt were important. For example, (1) What do you see as some of the main challenges newcomers are dealing with, including service restrictions such as service closures, physical distancing, little face-to-face interaction and service delivery? (2) What impacts do these closures have on their current jobs or their attempt to find one? What are the changes implemented by your agency to help them with continuous learning their language proficiency? (3) Since most newcomers have large families with small school-age children, what are the challenges or issues, including homeschooling and accessing support, they are dealing with during lockdown with the kids? (4) How are religious or communal activities used among newcomers to adjust and overcome this new self-isolation, restrictions? What steps are they taking to promote their wellbeing during this crisis, including opportunities you as a service provider share with your clients?

\section{Findings}

While discussing these issues, we explored service delivery changes. We found out that service providers working with marginalized groups and newcomers continue working as the pandemic poses various challenges for communities. Families dealing with problems at home, including homeschooling and caring for family, respond differently to the COVID-19 situation and service needs.

Service providers are still helping individuals and families deal with loneliness, anxiety, and depression while supporting and providing social support through online chats, phone calls, and face-to-face meetings. They help newcomers separated from their families during resettlement and COVID-19 travel restrictions with their feelings of anxiety and disappointment. Despite the challenges and health risks, face-to-face interaction with their clients remains one of the only systems maintained as providing social connections, serving as coping mechanisms and support structures they use during the pandemic. They see this as an essential aspect of their services for individuals with difficulties in their language ability, literacy, and other challenges. Having face-to-face conversations on self-isolating, navigating services, and self-care becomes an essential part of the work they do during COVID (Public Health Ontario, 2020).

\subsection{The Challenges of Service Restrictions}

During the pandemic, the service provider's identified how the temporary closure of settlementrelated services, including those issuing necessary documentation and identification services such as Social Insurance Numbers (SIN), driver's licenses, and health cards, contributed to significant challenges for specific populations. Similarly, service providers' support was delayed because of the lack of face-to-face interaction with newcomers. Moving services from in-person to virtual resulted in new challenges. Explaining and providing accurate information over the phone or online about community programs such as opportunities to improve language skills (LINC / ESL / ELT classes), government services, education, employment, and other local community connections became tough. During pre-COVID-19 times, service providers 
used to support newcomers in many ways, such as: helping them with transportation, accessibility and disability services, translation and interpretation services, one on one support for crisis counselling, access to food security resources, finding housing/accommodation, information on emergency and safety procedures, information on financial resources in Canada and the Canadian legal systems. Service restrictions related to COVID-19 made the implementation of these supports more challenging. Other additional challenges created by the lack of technology use and access, such as technical training challenges to use online apps and online communication systems. For some, lack of access to the internet or wireless connection served as the biggest challenge to access services adapted to COVID-19 safety measures. Despite having access to technology, the type of support needed requires face-to-face interactions for specific groups. As a result, service providers continue to make these interactions as accessible as possible for communities despite the challenges of working from home, within safety regulations of distancing, and wearing appropriate personal protective equipment like a face mask or face shield.

Each service provider shared how in the first two weeks of official closures anxieties and confusion played out regarding income, food sources, and rent payments. Their concerns amplified in the following two to three weeks, around the end of March and early April 2020. Many families began to experience challenges getting their children adequate access to technology to keep up with their education, especially supports such as homework clubs previously addressed by neighbourhood after-school programs, computers, or library access. In the weeks after COVID-19 until now, families have been dealing with prolonged confinement stressors and significantly limited resources for their children and an overarching, ongoing sense of uncertainty and change.

Issues of poverty and lack of resources for newcomers pre-dated COVID-19, including living with low income and living in social housing with limited outdoor resources. These issues are either amplified by the virus or sparked the conversation around food insecurity for low-income newcomer families and parents' ability to adequately navigate the educational system and resources available, given language and technology barriers. Some families staying in emergency shelters do not have fully functioning kitchens or fridges fit to store food for an entire family and rely on community food support programs to feed their families.

Some service providers discussed the efforts required of them to help reduce barriers during COVID-19 service restrictions. While many vulnerable community members depend on access to a local food bank, the service restrictions made accessing food security resources even more complicated than they already were. Some agencies closed, causing community members to seek support even farther away from their homes. With public transportation paused, it became more difficult for vulnerable groups to access the services still open. Many services closed down, either temporarily or permanently, while others reduced or changed their hours frequently to keep up with evolving safety measures with each step of the lockdown. As well, children and parents alike were being asked and encouraged to stay home. For many service providers, it became clear that new methods of providing resources were needed. Some decided that delivering (at a safe distance) food bank orders was the most reliable way to meet food security needs, while also creating a small window of time to offer social support. 


\subsection{Lack of Access to Technology, Income, and Transportation}

Many services creatively adapted their approach to following COVID-19 safety measures while also providing the necessary services for newcomers and refugees and other vulnerable groups. COVID-19 allowed for innovative ways to connect with our community members; however, a lack of access to technology, income, and/or transportation led to many services becoming inaccessible, with COVID-19 safety implementations like virtual appointments only, drive-through COVID-19 testing, and online home delivery services for groceries and prescriptions. While many community services shifted their approach to providing services only by phone, email, or scheduled appointments, those without access to technology could not access services or up-to-date information about services. Similarly, as services continued to adapt to ongoing public health safety directives, many relied on technology to communicate to community members the updated hours and ways to access service. With continued service provision changes and a continuous flow of new information regarding the COVID-19 pandemic online and through news media, those without technology access are left even further isolated from the rest of the world. As some services shifted online, other services shifted to curbside pick-up models or drive-through access for health care appointments, food bank pickups, and even COVID-19 testing. Even with sufficient language literacy and access to the technology needed to reach service providers and book appointments, if transportation is unavailable, the challenge remains.

\subsection{The Challenges of Finding Employment}

In discussing employment challenges, service providers explored how the COVID-19 lockdown halted job search activities, especially those wanting to improve their language skills. During the lockdown, the funded adult ESL (or FSL) classes became closed, rescheduled, or available through online technology. However, while technology can connect, it can also be a significant barrier for those who cannot access it. Without appropriate access to technology, in addition to the previously offered childminding services, barriers continue to exist for newcomers to participate in language courses virtually. Parental anxieties increased due to fear of the inability to improve the level of their language proficiency. Parents were concerned about homeschooling and the future of their children's education once schools resume. Many worry about whether the lockdown will impact finding jobs in the future since the lockdown brought employment opportunities to a standstill. Others worry about if they will be able to return to their previous position.

Talking about the challenges of service restrictions, the authors expanded the conversation about the unemployment issues created by COVID-19, especially those servicing the newest members of our communities, for example, the Syrian refugees. Since 2015 Canada resettled 25,000 refugees through its various humanitarian programs (IRCC, 2016; Endicott, 2017). These newcomers arrive with varied skills. Highly trained professionals face downward mobility and stress, from a lack of obtaining professional Canadian employment experience in their field or finding only precarious jobs. Their service needs are not limited to online support but face-to-face cultural-based communication and human contact-based intervention.

Close contact and cultural-based social support during unemployment are vital for the 
wellbeing of these new Canadians. Service providers acknowledged they are particularly becoming vulnerable to the effects of COVID-19 social distancing and self-isolation. Some talked about how these individuals will often call to speak to service providers about the impact this lockdown has on them while at the same time coping with losing their jobs or searching for one. Citizenship Immigration Canada reports that $93 \%$ of refugees utilize social support within their first year in Canada (IRCC, 2019). Five years later, $41 \%$ of refugees rely on social support, and $40 \%$ rely on social support ten years after their arrival in Canada (IRCC, 2016). Since this group of Syrian refugees falls with the five-year time-space, their need for social support, including service providers' reliance, is high during this crisis.

The government of Canada established financial programs to support those who had lost employment during or due to COVID-19. However, many of these programs required using technology to apply, to which vulnerable groups have limited access. Additionally, financial program eligibility requirements are challenging to understand due to financial jargon, making it extremely difficult for newcomers to navigate how to apply, what to apply for, and to know if they are, in fact, eligible. Service providers discussed how some newcomers felt hesitant to apply to programs, fearing that the wrong application and misunderstanding of the program could impact their status in Canada. As many services had to shut their doors to in-person interactions, this meant that community members could not access free internet, public computers, printers, and fax machines offered in community settlement services. This issue of technology access extends beyond employment. Service providers discussed how many resources and benefits require online applications or technology, such as applying for emergency social housing. In these moments, face-to-face social support can be crucial to succeeding in navigating resources.

\subsection{The Challenges of Home Schooling Children during COVID-19}

Access to technology came into sharp focus for service providers during this lockdown, given how low-income families often have inadequate technology access. They talked about how once schools closed, they made a list of students in their area needing technological support to maintain their now online education. Service providers began delivering necessary technical support to these students (i.e. Chromebooks and USB internet sticks). They discussed some of the challenges and bumps along the way, especially finding the parents who didn't know of these efforts and resources communicated by the school due to language barriers or lack of the knowledge needed to keep up with school memos and advocate for their children's needs. The positive side of this was that equity-based programs began to help parents. At the same time, service providers kept close tabs on ministry and school board developments communicating these developments to the parents in an accessible format (e.g. translating memos and disseminating as recordings instead of written texts) and supporting and advocating for them as needed.

Concerning the challenges of learning from home, parents who aren't proficient in English or French have found it challenging to support their children's learning. These families heavily rely on the eldest siblings (as young as 12 years old) to provide educational support, which introduces a challenge for these supporting siblings who also have their learning to keep up 
with.

In these discussions, service providers also addressed parental stressors as they struggled to keep their children calm in their houses or small apartments. Children want to play and practise the activities they enjoyed before COVID-19, such as going to school with friends or spending time in national or local parks. Parents focus on keeping the children occupied, fed, and engaged at home and negotiating with neighbours who complain of noise to keep the peace out of fear of what might happen if neighbours call the authorities.

\subsection{The Challenges of Social Gathering and Restriction of Religious Activities}

According to the World Health Organization (2020), for example, with the dramatic spread of COVID-19, millions of religious groups, including worldwide, cannot practise social and religious gatherings, a source of social connection and support. Governments worldwide have banned all types of meetings, including religious ones, and encouraged people to practise physical distancing. As a result, service providers discussed the impact this had on their clients from Muslim communities. They used as an example what happened during the month of Ramadan in 2020 that began right after the time when most lockdowns were in full force on April 24, 2020, and ended on May 24, 2020.

One of the service providers discussed how he encourages his Muslim clients to follow government rules honouring social distancing, just like the prophet Mohammad's teaching (peace be upon him), who taught Muslims how to respond to the events as pandemics. This service provider, in particular, talked about how he made service delivery holistic, matching his client's culture by discussing the importance of following COVID-19 restrictions.

Other service providers also mentioned how religious teachings helped their clients stay well mentally and physically through holistic discussions. This service format enabled clients to consider cancelling all social and religious gatherings and adjust accordingly by performing prayers with their spouses and children at their homes without the community or going to mosques, churches, and temples during the lockdown. Making social connection easier for clients by discussing or teaching those who do not know how to keep in contact with their families using video chats mobile applications shows commitment to service, which they all agreed.

\section{Service Providers Wellness during COVID-19}

It was interesting to hear how some service providers used religious activities to create a social buffering phenomenon essential to them. In our discussion, we noted the importance of having emotional and social connections during hard times as they discussed their intervention methods. For example, many of them described how prayer helped those strongly connected to their religious beliefs during this stressful time. Researchers say this comes from providing each other with emotional support and healing through internalized connections (Badenoch, 2017; Siegel, 2011). The need for internalized relations is not limited to humans, as many animals also engage in this balancing reaction. The impact of stress, such as the COVID-19 
lockdown and parental responsibility, correlates with the activation of the hypothalamicpituitary-adrenal gland axis and the production of stress hormones glucocorticoids cortisol (Levine, 2000). The overproduction of stress hormones impacts both mental and physical health. Researchers say it is human nature when facing danger to unconsciously secrete stress hormones to fuel escape because our brains and bodies are programmed to run for safety. During regular times, the body's hormonal balance is restored quickly when the danger passes, and stress hormones can come to rest, which is not the case during the pandemic and continued fear (Levine, 2000; van der Kolk, 2014). What is currently unknown is the long-lasting physical and mental health impacts of COVID-19 once the lockdown is over and the virus is under control.

\section{Conclusion}

As community members and service providers who participated in these discussions, the authors shared their insights on how COVID-19 has changed how community-based social services are delivered. For newcomers, migrants, and refugees, these impacts are distinct, and this paper serves as an opening to that discussion. We understand that these discussions are only scratching the surface of understanding how marginalized groups are among the most vulnerable to these impacts. The COVID-19 lockdown has created more barriers to providing and accessing services, putting vulnerable families into further isolation. Often when working with refugees and newcomers, it can be essential to work from a Trauma-Informed Care perspective, understanding that those fleeing war-torn areas bring significant trauma and experience (Levenson, 2017). When accessing services, it is crucial to ensure these community members can feel safe and welcomed, to help, offer corrective experiences and help them resettle effectively in their new homes with a sense of belonging. With many service restrictions in place (specifically, wearing masks, personal protective equipment, and maintaining a sixfoot distance), it can be challenging to uphold these practice methods in a way that makes community members feel welcome.

The COVID-19 pandemic shifted service provision entirely, with service providers improvising and thinking outside of the box to maintain the social support they provide to their community members while maintaining safety regulations and following strict lockdown protocols. Service providers, including one of the authors, have done their best to navigate these barriers alongside the families and lives they are supporting. As things so rapidly changed, both service providers and community members had to re-learn current safety regulations, lockdown procedures, and resources, in addition to experiencing the impacts of worry about the pandemic.

It is important to note that in these early stages of the COVID-19 pandemic, Canada's Government determined the Canada Emergency Response Benefits (CERB) would provide $\$ 2,000$ per month to those who lost their income due to COVID-19. Some noted how refugees and newcomers who arrive in Canada are offered monthly social assistance at a significantly lower rate (Monsebraaten, 2020). This difference between the government income support programs may speak to some of the challenges experienced by these families pre-COVID-19. The service providers say this decision alludes to a greater inequality that exists in Canada. If 
$\$ 2,000$ determines a monthly standard of living for Canadians, why are social assistance rates not the same?

For this reason, the authors of this text feel future research must focus on specific marginalized groups like refugees and newcomers who have additional barriers to face in addition to a global pandemic. More ethnic-centric data is needed to identify the distinct impacts of the pandemic for marginalized groups. When the dust clears, what lessons will remain? How will we measure and understand the differentiating implications for vulnerable groups? How can we learn from these experiences to better serve our communities?

The impacts of the COVID-19 pandemic continued to change the world's ways well into the year 2021. Emerging research exploring individuals and vulnerable groups' unique experiences is necessary to understand our society's health equity outcomes.

\section{Acknowledgment}

We acknowledge and thank all Ottawa and Toronto area service community providers who participated in this discussion and their ongoing commitment to service provision in these unprecedented times.

\section{References}

Alliance of Healthier Communities (2020). Statement from Black Health Leaders on COVID19 's impact on Black Communities in Ontario. Retrieved from https://www.allianceon.org/news/Statement-Black-Health-Leaders-COVID-19s-impactBlack-Communities-Ontario

Amoah, J. (2013). Narrative: The Road to Black Feminist Theory. Berkeley Journal of Gender, Law \& Justice, 12(1), 5.

Andersen, M. L., \& Collins, P. H. (2013). Race, Class, and Gender: An Anthology. Wadsworth, Cengage Learning

Badenoch, B. (2017). The Heart of Trauma: Healing the Embodied Brain in the Context of Relationships (Norton Series on Interpersonal Neurobiology).

Bill and Melinda Gates Foundation. (2020). When a COVID-19 vaccine is ready, this group will make sure the whole world can access it. Retrieved 13 July, 2020 from https://www.gatesfoundation.org/TheOptimist/Articles/coronavirus-gavi

Bowden, O. (May 2020). Canada's lack of race-based COVID-19 data hurting Black Canadians: experts. Global News. Retrieved from https://globalnews.ca/news/6892178/black-canadians-coronavirus-risk/

Bowden, O., \& Cain, P. (2020). Black neighbourhoods in Toronto are hit hardest by COVID19-and it's 'anchored in racism': Experts. Retrieved 12 July, 2020 from 
https://globalnews.ca/news/7015522/black-neighbourhoods-toronto-coronavirus-racism/

Brown, D. (2001). B.C. labour vows to fight government pro-business agenda. Canadian HR Reporter, 14(15), 1.

Brown, T. N., \& Williams, D. R., et al. (2000). "Being black and feeling blue": the mental health consequences of racial discrimination. Race and Society, 2(2), 117-131. https://doi.org/10.1016/S1090-9524(00)00010-3

Chadwick, K., \& Collins, P. (2015). Examining the relationship between social support availability, urban center size, and self-perceived mental health of recent immigrants to Canada: A mixed-methods analysis. Social Science \& Medicine, 128, 220-230. https://doi.org/10.1016/j.socscimed.2015.01.036

Chappell, R. (2014). Social Welfare in Canadian Society (5th ed.). Toronto: Nelson Education LTD.

Collins, P. H. (2000). Black Feminist Thought: Knowledge, consciousness, and the politics of empowerment. New York, NY \& London, UK: Routledge.

Collins, P. H. (2019). Intersectionality as Critical Social Theory. Duke University Press, Durham NC, US. https://doi.org/10.1215/9781478007098

De Haene, L., et al. (2010). Holding Harm: Narrative Methods in Mental Health Research on Refugee Trauma. Qualitative Health Research, 20(12), 1666. https://doi.org/10.1177\%2F1049732310376521

De Maio, F. G. (2010). Immigration as pathogenic: A systematic review of the health of immigrants to Canada. International Journal for Equity in Health, 9(1), 27. https://doi.org/10.1186/1475-9276-9-27

Elliot, A. (2003). Bill Gates boosts fight against virus that threatens three billion. $B M J$, 327(7428), 1366-b-0. https://doi.org/10.1136/bmj.327.7428.1366-b

Elliott, M., \& Hayward, R. D. (2009). Religion and life satisfaction worldwide: The role of government regulation. Sociology of Religion, 70, 285-310. https://doi.org/10.1093/socrel/srp028

Endicott, R. (2017). The Economic Integration of Canada's Refugees: Understanding the Issues with Canada's Approach, A research paper accepted in partial fulfilment of the requirements for the degree of Master of Arts. Retrieved from https://ir.lib.uwo.ca/cgi/viewcontent.cgi?article=1014\&context=sociology_masrp

Gates, B. (2015). The next outbreak? We're not ready. TedTalks. Retrieved from https://www.ted.com/talks/bill_gates_the_next_outbreak_we_re_not_ready?language=en

Guttmann, A., Gandhi, S., Wanigaratne, S., Lu, H., Ferreira-Legere, L. E., Paul, J., Gozdyra, P., Campbell, T., Chung, H., Fung, K., Chen, B., Kwong, J. C., Rosella, L., Shah, B. R., Saunders, N., Paterson, J. M., Bronskill, S. E., Azimaee, M., Vermeulen, M. J., \& Schull, M. J. (2020). COVID-19 in Immigrants, Refugees and Other Newcomers in Ontario: 
Characteristics of Those Tested and Those Confirmed Positive, as of June 13, 2020. Toronto, ON: ICES; 2020.

Hooks, B. (1984). Feminist theory: From margins to centre. Cambridge, MA: South End Press.

Immigration, Refugees and Citizenship Canada (IRCC). (2016). Evaluation of the Resettlement Programs (GAR, PSR, BVOR, and RAP). Retrieved from https://www.canada.ca/en/immigration-refugees-citizenship/corporate/reportsstatistics/evaluations/resettlement-programs.html

Immigration, Refugees, and Citizenship Canada (IRCC) (2019). Syrian Outcomes Report. Retrieved from https://www.canada.ca/en/immigration-refugeescitizenship/corporate/reports-statistics/evaluations/syrian-outcomes-report-2019.html

Levenson, J. (2017). Trauma-informed social work practice. Social Work, 62(2), 105. https://doi.org/10.1093/sw/swx001

Levich, J. (2015). The Gates Foundation, Ebola, and Global Health Imperialism. American Journal of Economics and Sociology, 74(4), 704-742. https://doi.org/10.1111/ajes. 12110

Levine, S. (2000). Influence of psychological variables on the activity of the hypothalamicpituitary-adrenal axis. European Journal of Pharmacology, 405(1-3), 149-160. https://doi.org/10.1016/S0014-2999(00)00548-3

McKenzie, K., \& Agic, B., et al. (2016). The Case for Diversity Building the Case to Improve Mental Health Services for Immigrant, Refugee, Ethno-cultural and Racialized $\begin{array}{llll}\text { Populations } & \text { [PDF } & \text { File]. } & \text { Retrieved }\end{array}$ https://www.mentalhealthcommission.ca/sites/default/files/2016-10/case_for_diversity_ oct_2016_eng.pdf

Monsebraaten, L. (2020). Open Letter urges Ontario to boost support for people on social assistance. Retrieved from https://www.thestar.com/news/gta/2020/04/07/open-letterurges-ontario-to-boost-support-for-people-on-social-assistance.html

Oluwatayo, I., \& Ojo, A. (2018). Walking Through a Tightrope: The Challenge of Economic Growth and Poverty in Africa. The Journal of Developing Areas, 52(1), 59-69. https://doi.org/10.1353/jda.2018.0004

Pargament, K. I., \& Park, C. L. (1997). In times of stress: The religion-coping connection. In B. Spilka, \& D. N. McIntosh (Eds.), The psychology of religion: Theoretical approaches (pp. 43-53). Boulder, CO: Westview Press.

Park, C. L. (2005). Religion and meaning. In R. F. Paloutzian, \& C. L. Park (Eds.), Handbook of the psychology of religion and spirituality (pp. 295-314). New York, NY: Guilford Press.

Parker, R. (2002). The global HIV/AIDS pandemic, structural inequalities, and the politics of international health. American Journal of Public Health, 92(3), 343-346. https://doi.org/10.2105/AJPH.92.3.343

Public Health Ontario. (2020). Coronavirus Disease 2019 (COVID-19): How to Self-Isolate. 
Retrieved from https://www.publichealthontario.ca/-/media/documents/ncov/factsheetcovid-19-how-toselfisolate.pdf?la=en\&hash=DE0D90F7BCD3C43A65E8ED98433BDE74887ACB20

Raphael, D. (with Rainer, R. \& Layton, J.). (2011). Poverty in Canada: Implications for health and quality of life. Toronto, ON: Canadian Scholars' Press Inc.

Siegel, D. (2011). Mindsight: The new science of personal transformation. New York, NY: Bantom Books.

Simich, L., Beiser, M., \& Stewart, M., et al. (2005). Providing Social Support for Immigrants and Refugees in Canada: Challenges and Directions. J Immigrant Health, 7, 259-268. https://doi.org/10.1007/s10903-005-5123-1

Statistics Canada. (2019). New immigrants made up $61 \%$ of Canada's population growth in 2018. Retrieved from https://www.cicnews.com/2019/03/new-immigrants-made-up-61of-canadas-population-growth-in-2018-0312086.html\#gs.6rnm9g

Stöhr, K. (2005). Avian Influenza and Pandemics - Research Needs and Opportunities. The New England Journal of Medicine, 352(4), 405-407. https://doi.org/10.1056/NEJMe048344

Tracy, S. J. (2013). Qualitative research methods: Collecting evidence, crafting analysis, communicating impact. Oxford, UK: Wiley-Blackwell.

Van der, K., \& Bessel, A. (2014). The body keeps the score: Brain, mind, and body in the healing of trauma. New York: Viking.

Wahl, A. (2011). The Rise and Fall of the Welfare State, London: Pluto Press. The attacks, 5, 93-125.

Webster, L., \& Mertova, P. (2007). Using narrative inquiry as a research method: An introduction to using critical event narrative analysis in research on learning and teaching. Routledge/Taylor \& Francis Group. https://doi.org/10.4324/9780203946268

World Health Organization (2020). Infection prevention and control guidance for long-term care facilities in the context of COVID-19: interim guidance, March 21, 2020. World Health Organization.

\section{Copyrights}

Copyright for this article is retained by the author(s), with first publication rights granted to the journal.

This is an open-access article distributed under the terms and conditions of the Creative Commons Attribution license (http://creativecommons.org/licenses/by/4.0/) 